\title{
Experiment on Behavior of a New Connector Used in Bamboo (Timber) Frame Structure under Cyclic Loading
}

\author{
Junwen Zhou $\mathbb{D}^{1,2}$ Dongsheng Huang $\mathbb{D}^{1},{ }^{1}$ Chun Ni, ${ }^{3}$ Yurong Shen, ${ }^{1}$ and Longlong Zhao ${ }^{1}$ \\ ${ }^{1}$ School of Civil Engineering, Nanjing Forestry University, Nanjing 210037, China \\ ${ }^{2}$ School of Civil Engineering and Architecture, Changzhou Institute of Technology, Changzhou 213033, China \\ ${ }^{3}$ FPInnovations, Vancouver, BC, Canada V6T 1Z4, \\ Correspondence should be addressed to Dongsheng Huang; dshuang@njfu.edu.cn
}

Received 16 September 2017; Revised 5 January 2018; Accepted 29 January 2018; Published 14 March 2018

Academic Editor: Ana S. Guimarães

Copyright ( 92018 Junwen Zhou et al. This is an open access article distributed under the Creative Commons Attribution License, which permits unrestricted use, distribution, and reproduction in any medium, provided the original work is properly cited.

Connection is an important part of the bamboo and timber structure, and it directly influences the overall structural performance and safety. Based on a comprehensive analysis of the mechanical performance of several wood connections, a new connector for the bamboo (timber) frame joint was proposed in this paper. Three full-scale T-type joint specimens were designed to study the mechanical performance under cyclic loading. The thickness of the hollow steel column was different among three specimens. The specimens were loaded under displacement control with a rate of $10 \mathrm{~mm}$ per minute until the specimens reach failure. It was observed that the failures of three specimens were caused by the buckling of flanges in the compression and that the steel of connections does not yield. The load-displacement hysteretic curve for three specimens is relatively plump, and the stiffness of connection degenerates with the increasing of cyclic load. The maximum rotation is $0.049 \mathrm{rad}$, and the energy dissipation coefficient is 1.77 . The thickness of the hollow steel column of the connector has significant impact on the energy dissipation capacity and the strength of the connection. A simplified moment-rotation hysteresis model for the joint was proposed.

\section{Introduction}

Timber is a natural organic material, and people easily get it from nature and use it without much processing; therefore, timber was employed as a construction material a long time ago. Timber has higher strength in tension and compression parallel to grain, light mass, and good durability, some 1000year timber buildings still stand well [1]. Because of friendly environment, graceful timber texture, and simple nature, timber building will still be enormously appealing to people. For the timber frame structure, the beam-to-column connection is usually the most unsubstantial part on account of fabricated construction. The mechanical behavior of timber joints directly influences the overall timber structural performance and safety. As a result, the design of timber joints is extremely important. In some Asian countries such as China, South Korea, and Japan, mortise and tenon joints [1-5] are traditionally used in timber buildings from dwelling houses to palaces. In these joints, steel fasteners are not used, therefore keeping the original beauty of the timber. However, due to the slippage between the mortise and tenon, the energy dissipation capacity of the whole structure is affected under earthquake load. The whole building can even collapse due to the separation between the mortise and tenon. In addition, the mortise-to-tenon connection wakens the column cross section at the connection, which reduces the vertical loadcarrying capacity and also negatively affects the energy dissipation capacity of the column. To prevent the mortise-totenon connection from separation and improve the strength of connection, Bulleit et al. [6] used wooden pegs to fasten mortise-to-tenon connection. But the study showed that the split failure owes to prying force of the wood peg occurred along with a peg hole when there is a distance between the tenon and the sill of mortise, and either shear failure of the tenon appeared. Moreover, Hong et al. [7] employed a T-type steel plate to strengthen the mortise-to-tenon connection and not to enhance the energy dissipation capacity of the joint.

Steel plate-bolted connection is another joint commonly used to connect the beam and column in a timber structure, which often is applied in the heavy timber structure and has 
architecture beauty because the connecting steel plate is covered with wood. However, for these types of joints, the brittle failure mode was obvious [8-10]. Split failure along the bolt hole in the beam is the main failure mode in this kind of joint, and it reduces the load-carrying capacity of the joint. As the beam and column are slotted to accommodate the steel plate, the vertical load-carrying capacity is reduced. Under cyclic loading, the hysteretic curve shows a clear "pinching" effect because of the gap between the bolt and wall of the hole [8-10].

Glued-in-rod connection is also commonly used to connect the beam and column in a timber building. The rod is embedded in timber to connect the beam and column and to transfer the load from the beam to the column. With appropriate materials and good construction quality, the glued-in-rod connection has demonstrated good structural performance $[11,12]$. The glued-in-rod connection has been widely studied and used in various projects [13]. The advantage of glued-in-rod connection is that the steel rod is embedded in timber to protect the steel rod from corrosion, and the durability is better. In order to get good construction quality, generally, the steel rod should be glued well with one timber first part in advance and then being connected with another part. Thus, the rod hole position on the beam and column must be precise. As timber and glue are brittle materials, the principle of energy dissipation is not obvious. Vašek $[14,15]$ used two U-type steel connectors located at upper and bottom edges of the beam to fasten the steel rods embedded in the timber beam and column. This new method could reduce stress concentration to the beam and column and increase the energy dissipation capacity of the joint by the deformation of U-type steel connectors. In addition, the U-type steel connectors are applied to connect the timber beam and column, and the position of the hole on the steel connector can easily be changed, which is convenient for connection construction on site.

Bolted timber-timber connection is a simple and practical connection for the timber beam-to-column joint. Only bolts are used to fasten the timber beam and column and to carry load from the girder to the post $[16,17]$. Steel nails sometimes are used to substitute for bolts. The different mechanical performance of connection can be obtained by changing the quantity and arrangement style of bolts. Some special materials, such as steel plate or hard wood, are inserted into the contacted surface of the beam and column to improve the performance of connection as well.

For the timber beam-to-column joint, load-carrying capacity and energy dissipation are the two primary factors to judge the performance of the joint. Huang [18] gave a better energy dissipation connector for the timber frame joint, but the connection between the beam and column is not robust, slippage happens under earthquake, and shear stiffness of the joint is less. Based on the comprehensive analysis of the abovementioned joints, a new beam-tocolumn connector was developed and presented in this paper. The joint can connect top and bottom columns and also link beam and column parts without weakening the column cross section. As the mechanical behavior of this joint under the earthquake load is unknown, an experimental study was conducted to evaluate the stiffness, strength, energy dissipation, and resilience of the joint with different thicknesses of the hollow steel column.

\section{Joint Details and Fabrication}

The joint consists of two parts. One part is beam and column members made of parallel strand bamboo (PSB) [19-21]. The beam is $55 \mathrm{~mm}$ in width, $200 \mathrm{~mm}$ in depth, and $1050 \mathrm{~mm}$ in length. Two beams were assembled in parallel. At the end of the beams where a bolt hole was located, carbon fiberreinforced plastic, $8 \mathrm{~mm}$ in width, was used to wrap the beams to prevent it from cracking along the bolt hole. The top and bottom columns are $200 \mathrm{~mm}$ in width, $240 \mathrm{~mm}$ in depth, and $700 \mathrm{~mm}$ in length. The column depth is paralleled to the beam axis. The other part is a steel connector, which is the most important part of the joint. The details of the connector are shown in Figure 1. Four steel plates are welded together to form a hollow column, and then, a horizontal steel plate is welded in the middle of the hollow column to reinforce the hollow column and to transfer load from the top column to the bottom column. The top and bottom plates (flanges) of the I-shaped steel beam were bent into L shape and welded to the hollow steel column. A steel plate web was welded between the top and bottom flanges to form an I-shaped steel beam. Two shear connection plates were welded to the hollow steel column and fastened to the web of the I-shaped steel beam with a $16 \mathrm{~mm}$ diameter bolt. This is to ensure the connection between the hollow steel column and the I-shaped steel beam in case the welding between the hollow steel column and I-shaped steel beam flanges is broken.

The PSB columns were placed into the hollow steel column and connected to the hollow steel column with four $14 \mathrm{~mm}$ diameter bolts. Two PSB beams were connected to the steel web with four $16 \mathrm{~mm}$ diameter bolts.

\section{Description of the Experiment}

3.1. Specimen Designing. Three joint specimens were fabricated in site. Except for the thickness of the hollow steel column, the specimens are identical. Details of the specimens are shown in Figure 2. Holes in bamboo specimen (beam and column) and steel plate are $1.5 \mathrm{~mm}$ greater than those of bolts, which is easy to assemble. A detailed description of thickness of each tested steel connection plate is reported in Table 1.

3.2. Mechanical Properties of Materials. All the steel plates are of grade Q235B in accordance with the Chinese standard (GB/T700-2006) [22]. The material properties of the steel plates are determined according to EN10002-1 [23]. Table 2 lists the mechanical properties of the steel plates. The $14 \mathrm{~mm}$ diameter bolts, which were used to fasten the hollow steel column and PSB columns, had the average yield strength of $804 \mathrm{MPa}$ under tension. The $16 \mathrm{~mm}$ diameter bolts had the average yield strength of $2241 \mathrm{MPa}$ under bending.

According to the ASTM standard D143-09 [24], the ultimate compressive and tensile strength values of PSB parallel to grain are $65 \mathrm{MPa}$ and $100 \mathrm{MPa}$, respectively, and the ultimate tensile strength value of PSB perpendicular to grain is $4.4 \mathrm{MPa}$. 


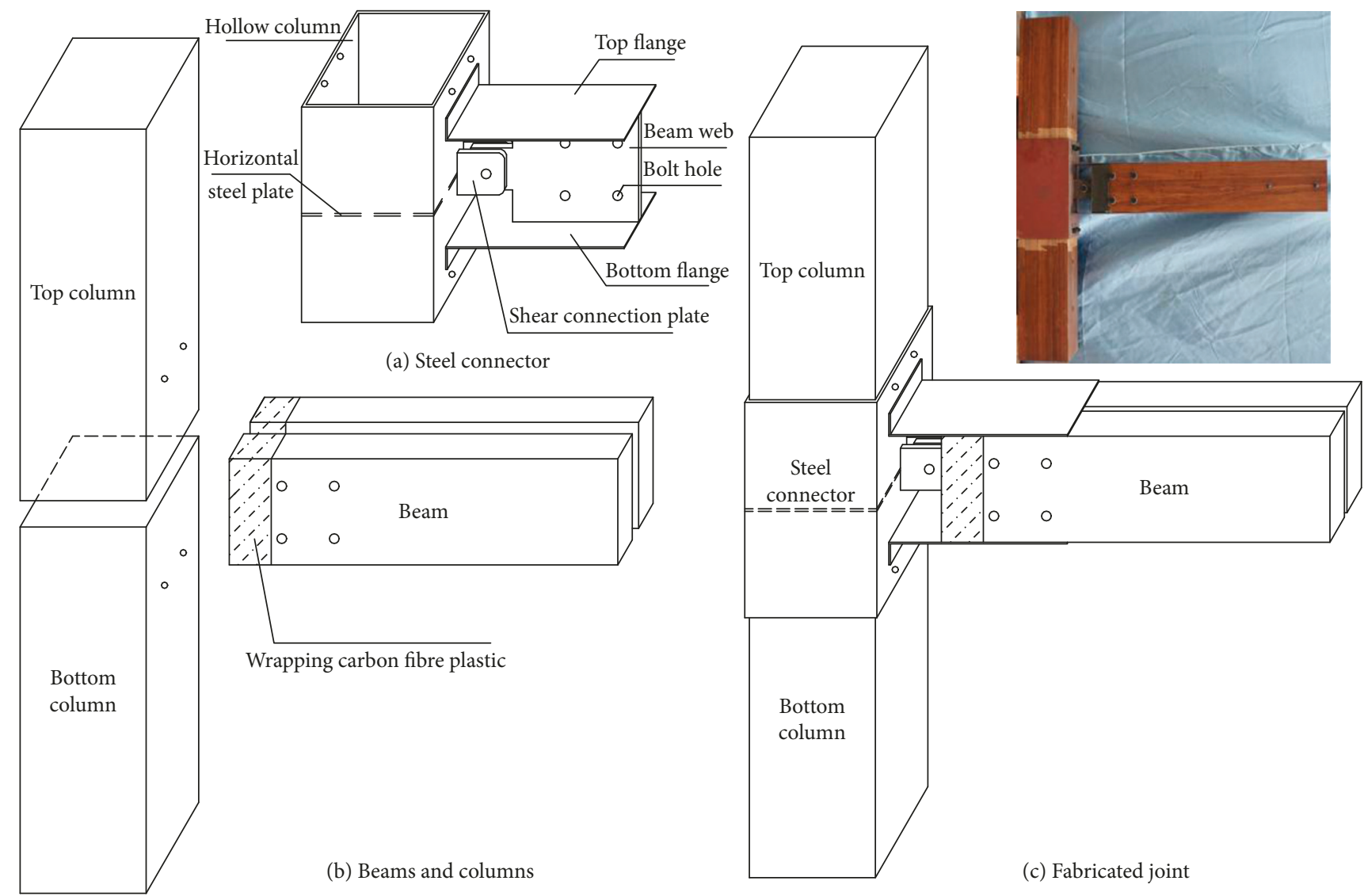

Figure 1: Constructional detail of the joint. (a) Steel connector, (b) beams and columns, and (c) fabricated joint.

3.3. Test Setup. A schematic illustration of the test setup is shown in Figure 3. The main purpose of this research is to study the mechanical performance of the connection specimens under cyclic loading. In order to load the specimen with the existing loading frame, the column was rotated an angle of $90^{\circ}$ and was fixed to the floor channel with four $30 \mathrm{~mm}$ diameter bolts. A two-way $250 \mathrm{~mm}$ hydraulic actuator ( $100 \mathrm{kN}$ capacity) was used to apply the cyclic load. The center of the actuator was $1000 \mathrm{~mm}$ above the top surface of the PSB column, and the head of the actuator was about $150 \mathrm{~mm}$ away from the PSB beam.

The beam displacements were monitored by a laser displacement sensor, and the corresponding load value was measured by a load cell mounted on the actuator rod. Two laser displacement sensors \#3 and \#4 were located at the beam flange to measure the rotation of the connection. The other two sensors \#1 and \#2 were located at the hollow steel column to measure the defection of the hollow column.

For the three specimens, the sensors were located at the same locations of the specimen.

3.4. Loading Schedule. In this study, a controlled cyclic displacement scheme was used. The maximum displacement was $10 \mathrm{~mm}$ in the first two cyclic loading, and the loading rate was $10 \mathrm{~mm}$ per minute. The maximum displacement was then increased by $10 \mathrm{~mm}$ after each step until specimen failure which showed specimen lost bearing loading capacity. The loading scheme is shown in Figure 4.

It was assumed that the actuator force in compression was positive, and the beam displacement moving away from the reaction wall was positive.

\section{Test Results and Analysis}

The test results of the three specimens are shown in Table 3. For each experiment, the failure mode, the energy dissipation, and the resilience model of each specimen will be discussed in the following sections.

4.1. Failure Mode. From Figure 3, it can be observed that one lateral beam flange was pulled and the opposite beam flange was compressed under loading. For the three specimens, the failure occurred when the beam flange buckled under compressive force. Figures 5-7 show the failure mode of the three specimens. It was noticed that the beam flange buckling occurred suddenly without yielding of the steel plate, which is a brittle failure and results in the failure of test specimens. Besides the beam flange buckling, for the specimen CJ2 in which the hollow steel column is $4 \mathrm{~mm}$ in thickness, the hollow steel column was also deformed around the beam flange because of tensile fore of the beam flange. The bolts and PSB members with larger cross-sectional dimensions were still in good condition after the tests. 


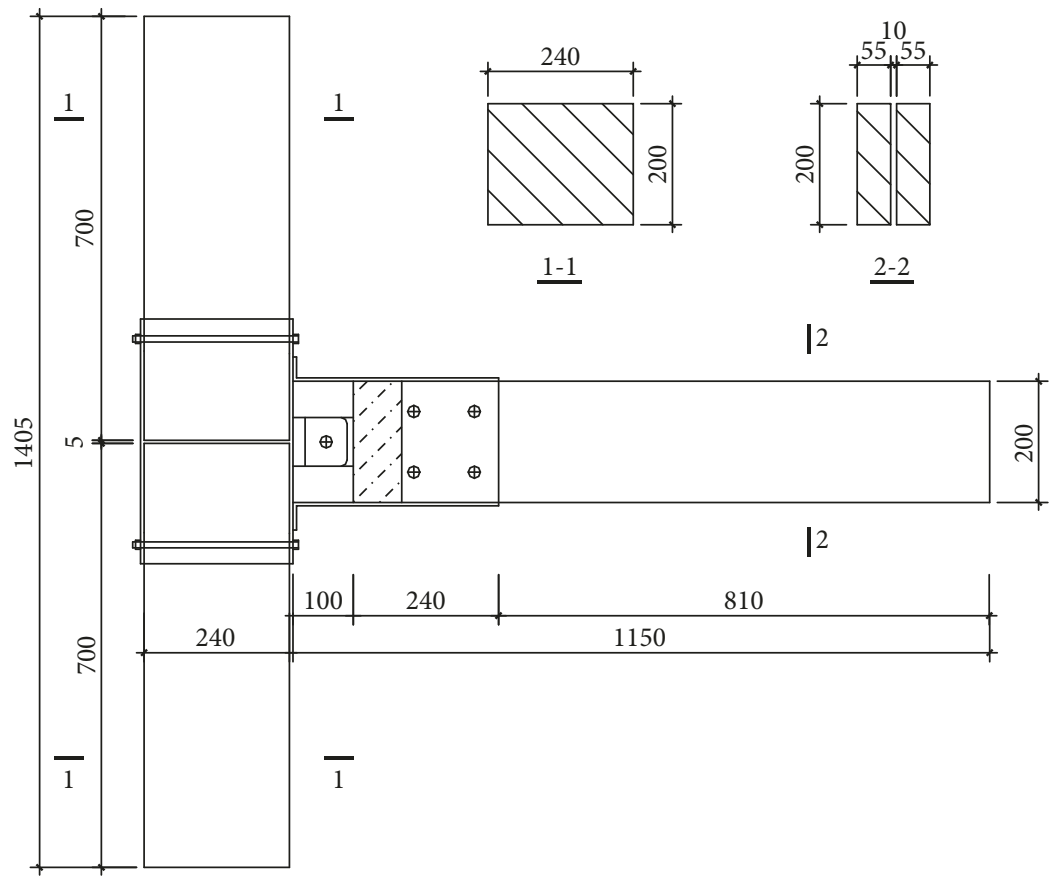

(a) Detailed drawing for joint.
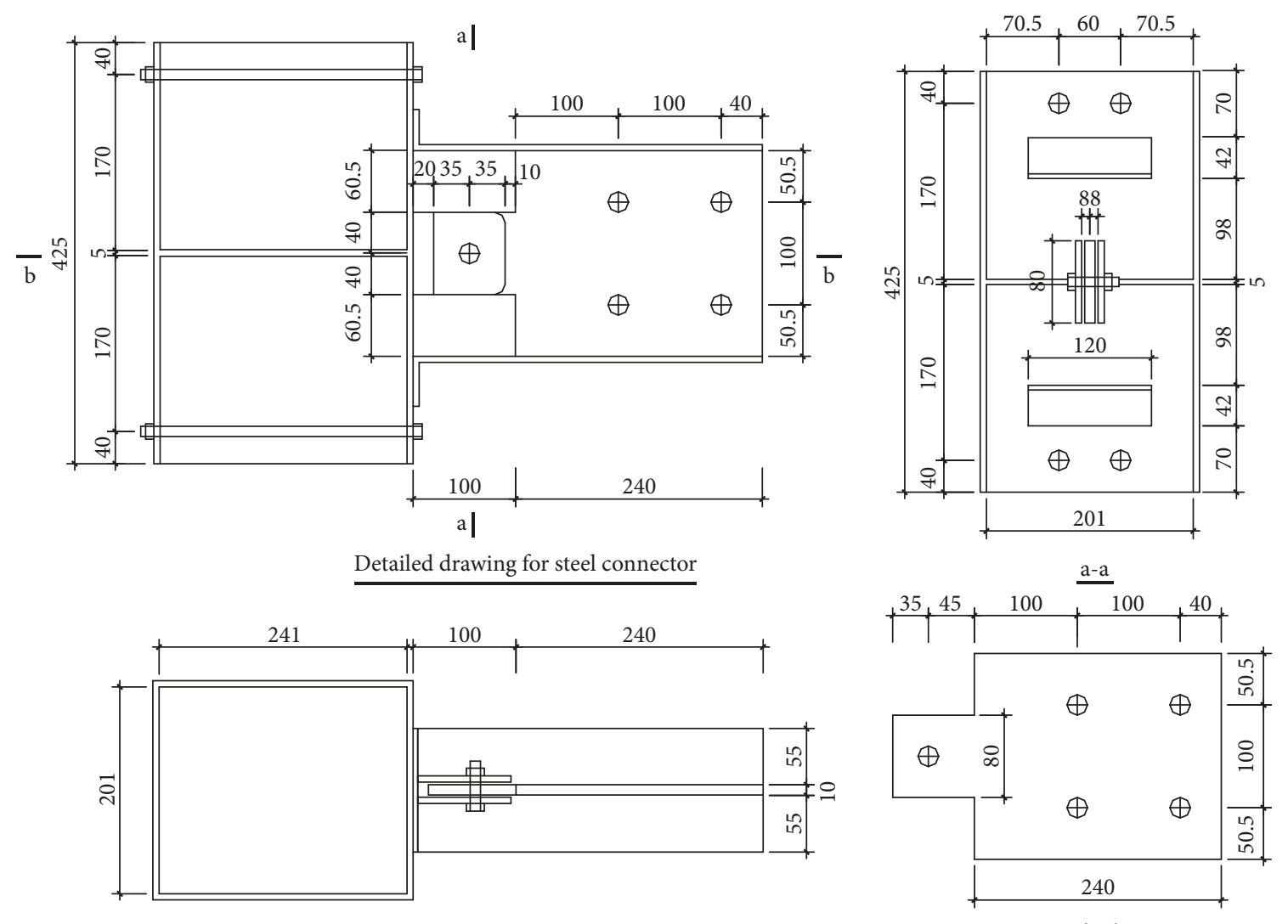

b-b

Web plate

(b) Detailed diagramtic drawing for steel connector.

Figure 2: Detailed parameters for the specimen (mm). 
TABLE 1: Steel plate thickness of the connector ( $\mathrm{mm})$.

\begin{tabular}{lccccc}
\hline Specimen & Hollow steel column & Beam flange & Beam web & Shear connection plate & Hollow column stiffener \\
\hline CJ1 & 5 & 3 & 10 & 8 & 5 \\
CJ2 & 4 & 3 & 10 & 8 & 5 \\
CJ3 & 6 & 3 & 10 & 8 & 5 \\
\hline
\end{tabular}

Grade Q235B is available for all steel plates.

TABLE 2: Mechanical property of the steel plate.

\begin{tabular}{|c|c|c|c|c|c|}
\hline Thickness of the steel plate (mm) & $\sigma_{y}(\mathrm{MPa})$ & $\sigma_{u}(\mathrm{MPa})$ & $\varepsilon_{y}(\%)$ & $\varepsilon_{u}(\%)$ & $E_{s}(\mathrm{MPa})$ \\
\hline 3 & 263 & 372 & 1.983 & 18.32 & 19523 \\
\hline 4 & 256 & 381 & 1.831 & 20.23 & 19871 \\
\hline 5 & 260 & 358 & 1.920 & 19.56 & 20522 \\
\hline 6 & 249 & 363 & 1.853 & 18.92 & 20246 \\
\hline 8 & 251 & 368 & 1.915 & 19.014 & 20042 \\
\hline 10 & 238 & 375 & 2.052 & 18.76 & 19197 \\
\hline
\end{tabular}

$\sigma_{y}$ is the yield stress; $\sigma_{u}$ is the limit stress; $\varepsilon_{y}$ is the yield strain; $\varepsilon_{u}$ is the limit strain; $E_{s}$ is the elasticity modulus.

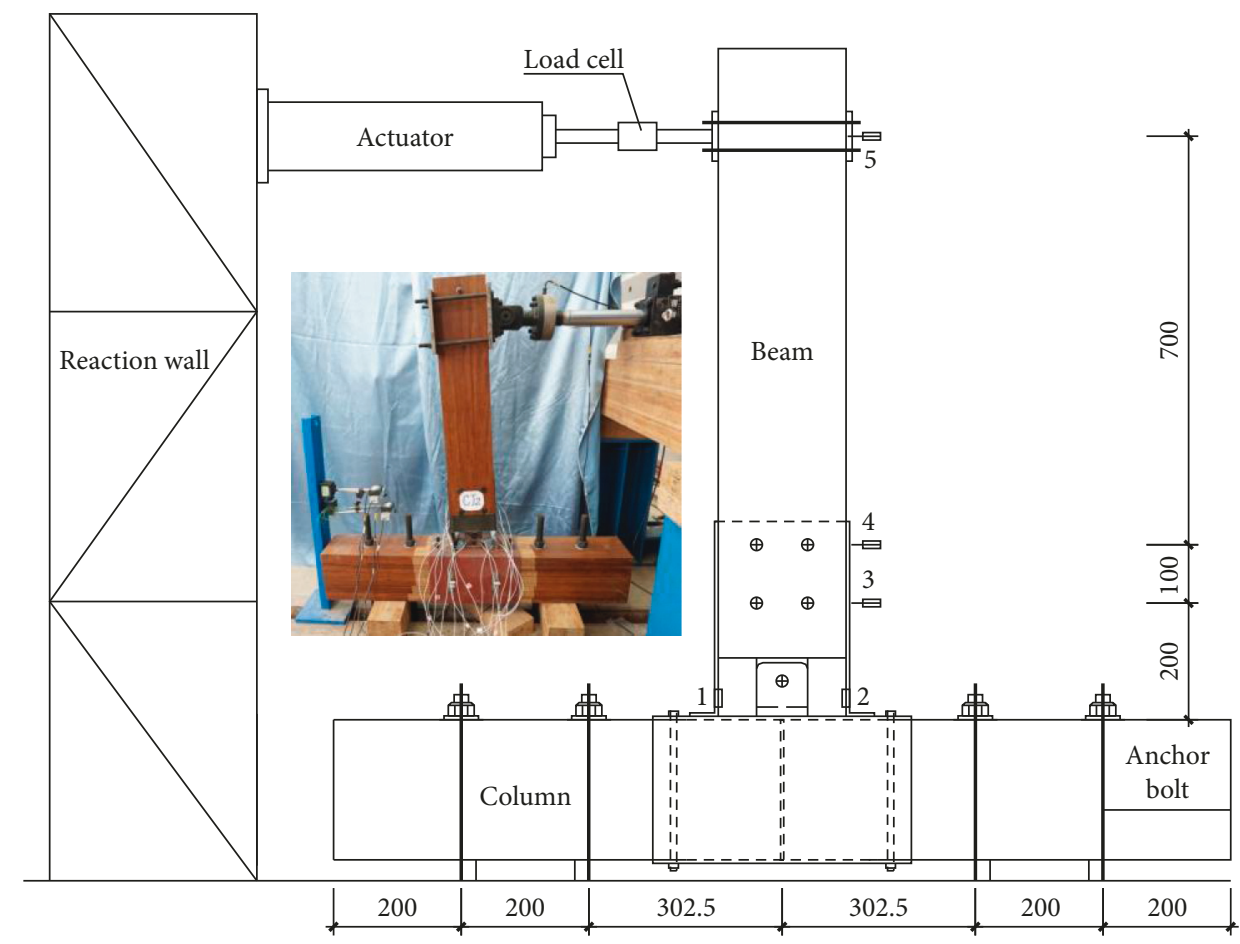

$\longrightarrow$ Laser displacement sensor

Figure 3: Experiment setup (mm).

According to tested results, it was also observed that the three specimens with the same thickness in the beam flange lost capacity in the same location and for the same reason, but they had obvious difference in ultimate bearing capacity; the main reason was that the boundary conditions of the compressed beam flange were not ideal situation under axial loading.

4.2. Load-Displacement Hysteretic Loop at the End of the Beam. The load-displacement hysteretic curve of the joint reflects the overall performance of connection. The load-displacement hysteretic curves at the end of the beam are shown in Figures 8-10. As can be seen from the figures, all three specimens exhibit good performance. The strength deterioration with the progress of the cyclic load was not observed. The rotational stiffness, however, deteriorated with the increase of cyclic load.

For the specimen CJ2 (4 mm thick hollow steel column), the beam flange in compression buckled suddenly after 9 displacement cycles. For the specimen CJ1 $(5 \mathrm{~mm}$ thick hollow steel column) and the specimen CJ3 $(6 \mathrm{~mm}$ thick hollow steel column), the beam flange in compression buckled suddenly after 8 displacement cycles. 


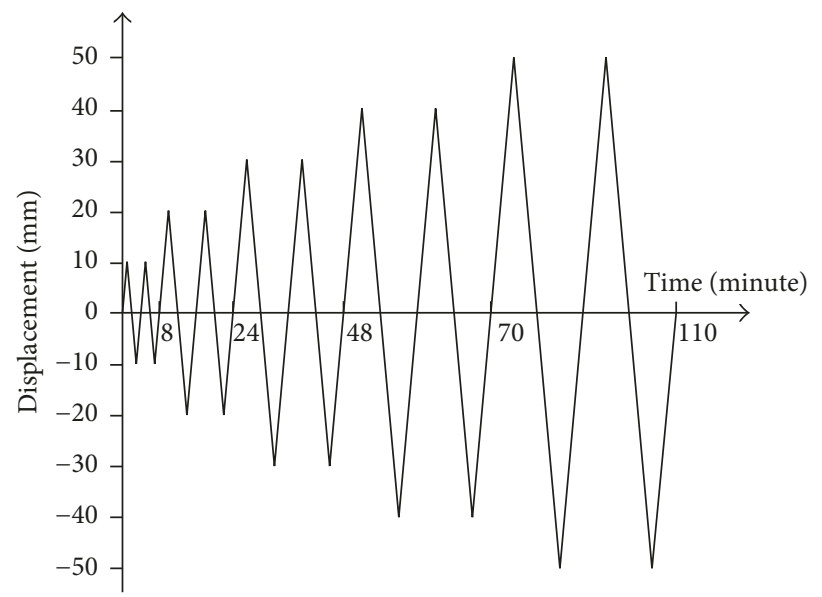

FIGURE 4: Loading scheme for the experiment.

TABLE 3: Test results of the three specimens.

\begin{tabular}{lccc}
\hline Specimen & $P_{\max }(\mathrm{kN})$ & $U_{\max }(\mathrm{mm})$ & Failure mode \\
\hline CJ1 & -8.56 & -39.19 & Compressed buckling of the beam flange \\
CJ2 & 10.20 & -50.00 & Compressed buckling of the beam flange \\
CJ3 & 11.92 & 48.57 & Compressed buckling of the beam flange \\
\hline
\end{tabular}

$P_{\max }$ is the maximum load value documented in a test. $U_{\max }$ is the maximum displacement value documented at summit from sensor \#5 in a test.

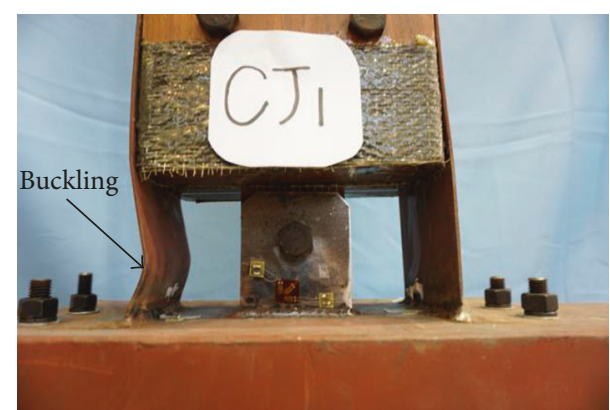

Figure 5: Beam flange buckled under compression for the specimen CJ1.

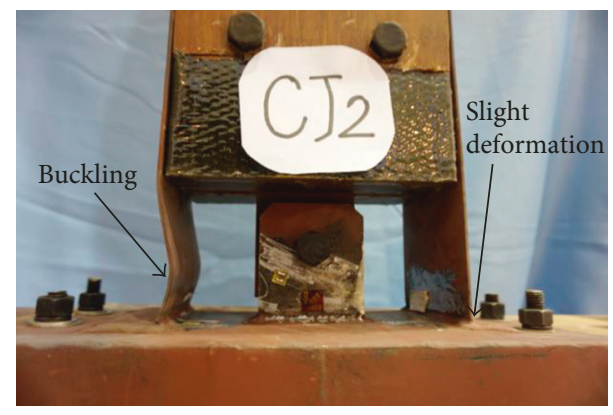

Figure 6: Beam flange buckled under compression for the specimen CJ2.

Figure 9 shows that the load in the specimen CJ2 is asymmetric. This indicates that the stiffness in positive direction is larger than that in negative direction.

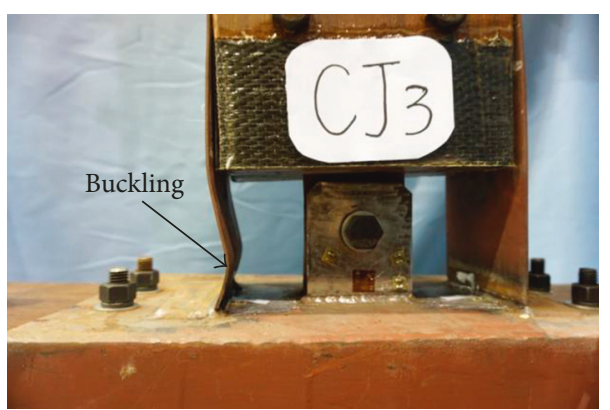

Figure 7: Beam flange buckled under compression for the specimen CJ3.

Slight pinching of load-deflection hysteretic curves was observed in all three specimens. Such a phenomenon may be contributed to the following reasons: on one hand, because of the gap of the bolt connection between the shear connection plate and the bolt, slippage is inevitable under the cyclic loading; on the other hand, shear deformation is not ignored due to less effective antishear section dimension in the bearto-column connection; of course, the deformation of the hollow column frame plate also contributes to the slippage.

4.3. Moment-Rotation Relationship Curve. Because of the large cross section of the PSB column, the stiffness of the column is quite large. As a result, it is assumed that there is no rotation in the column. Furthermore, as the PSB columns were fixed to the floor by four $30 \mathrm{~mm}$ diameter bolts, it was assumed that the PSB column did not slide under the cyclic loading. Based on the above assumptions, the rotation of 


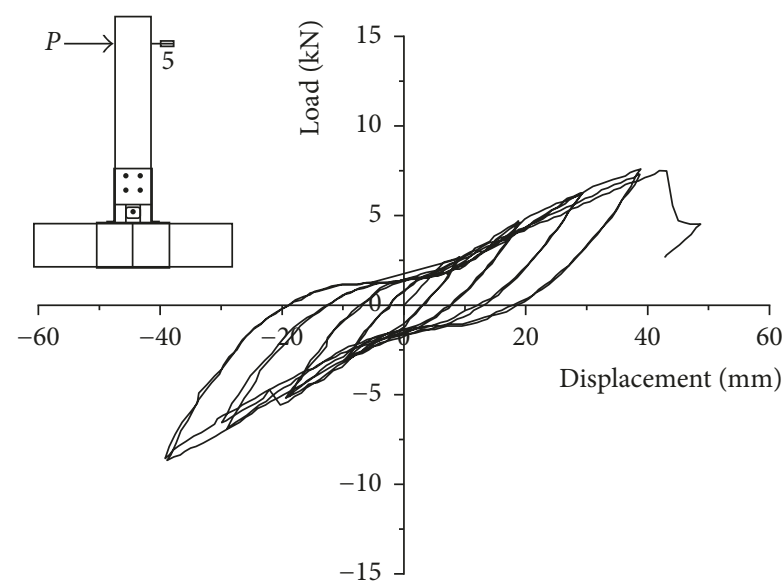

FIGURE 8: Load-displacement hysteretic loop of the specimen CJ1.

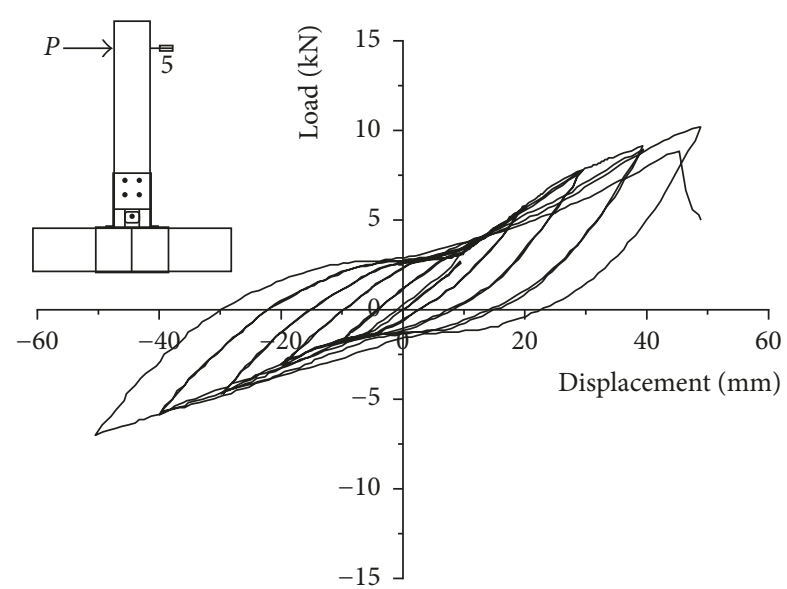

FIGURE 9: Load-displacement hysteretic loop of the specimen CJ2.

connection is the sum of the rotation due to the deflection of the hollow steel column, deflection of the beam flange, and the gap between the bolt and shear connection plate. In this test, the rotation of connection can be calculated as follows:

$$
\varphi=\arctan \left(\frac{\Delta_{4}}{300}\right)
$$

where $\Delta_{4}$ is the displacement of laser sensor \#4 under cyclic loading and 300 is the distance from sensor \#4 to the surface of the column.

When calculating the rotation of the joint, the displacements from sensors \#3, \#4, and \#5 all can be used. However, the displacement of sensor $\# 5$ includes the elastic deformation of the PSB beam, so the result from sensor \# 5 cannot be used to calculate the joint rotation. As for sensor \#3, which was placed at $100 \mathrm{~mm}$ away from the beam flange where beam web ends, the velocity of reciprocating deformation of the beam flange which is lagging behind the loading velocity in the beam tip affects the result of sensor \#3; therefore, the rotation of the joint based on sensor \#3 is not used.

The maximum rotation for each specimen is shown in Table 4. It is noted that the rotation for the specimen CJ2 with a $4 \mathrm{~mm}$ thick hollow steel column is the biggest among

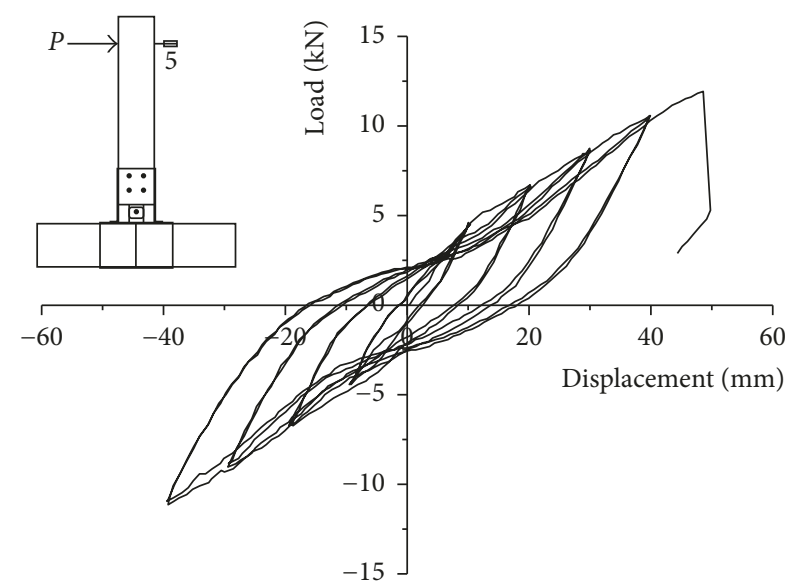

FIgURE 10: Load-displacement hysteretic loop of the specimen CJ3.

the three specimens. The specimen CJ3 with a $6 \mathrm{~mm}$ thick hollow steel column has the least rotation.

Because the deformation of the column is not taken into account, the moment of the joint is obtained by multiplying the load and the length from the loading point to the surface of the column. The equation for joint moment is given as follows:

$$
M=P \times L_{\text {load }},
$$

where $P$ is the load applied to the beam and $L_{\text {load }}$ is the distance from the load point to the upper surface of the column.

Figures 11-13 show the moment-rotation hysteretic behavior of the three specimens. It shows that, for all three specimens, the hysteretic behavior is stable until the buckling of the beam flange.

The initial stiffness $K_{\text {ini }}$ of each specimen, which is the ratio of the maximum moment to the corresponding rotation in the first cycle, is shown in Table 4. The initial stiffness increases with the increasing thickness of the hollow steel column. The relative parameters for the momentrotation curve of the three specimens are showed in Table 4.

4.4. Envelope Curve. Envelope curve is defined as the line which connects the maximum rotation and corresponding moment in the first cycle of the displacement step. Figure 14 shows moment-rotation envelope curves of the three specimens. It is noted that the envelope curve of each specimen is similar.

Yielding phenomenon was not observed in the whole envelope curve, but the load increase appears to slow down with the increase of cyclic displacement. Such a phenomenon is mainly due to substantial losses in stiffness of the beam flange and hollow steel column under cyclic loading. It is evident that the thickness of the hollow steel column has a significant influence on the envelope curve.

From the envelope curves in the third quadrant shown in Figure 14, the specimen CJ3 has the largest load and the specimen CJ1 has the smallest load at the same displacement. This corresponds to the thickness of the hollow steel column of 
TABle 4: Test results.

\begin{tabular}{|c|c|c|c|c|}
\hline Specimen & Loading direction & $M_{\max }(\mathrm{kN} \cdot \mathrm{m})$ & $\Phi_{\max }(\mathrm{rad})$ & $K_{\text {ini }}(\mathrm{kN} \cdot \mathrm{m} / \mathrm{rad})$ \\
\hline \multirow{2}{*}{ CJ1 } & Push & 7.58 & 0.0375 & \multirow{2}{*}{333} \\
\hline & Pull & -8.65 & -0.0375 & \\
\hline \multirow{2}{*}{$\mathrm{CJ} 2$} & Push & 10.2 & 0.049 & \multirow{2}{*}{221} \\
\hline & Pull & -7.00 & -0.0465 & \\
\hline \multirow{2}{*}{$\mathrm{CJ} 3$} & Push & 11.92 & 0.044 & \multirow{2}{*}{354} \\
\hline & Pull & -11.14 & -0.039 & \\
\hline
\end{tabular}

Note. $\Phi_{\max }$ corresponds to $M_{\max }$.

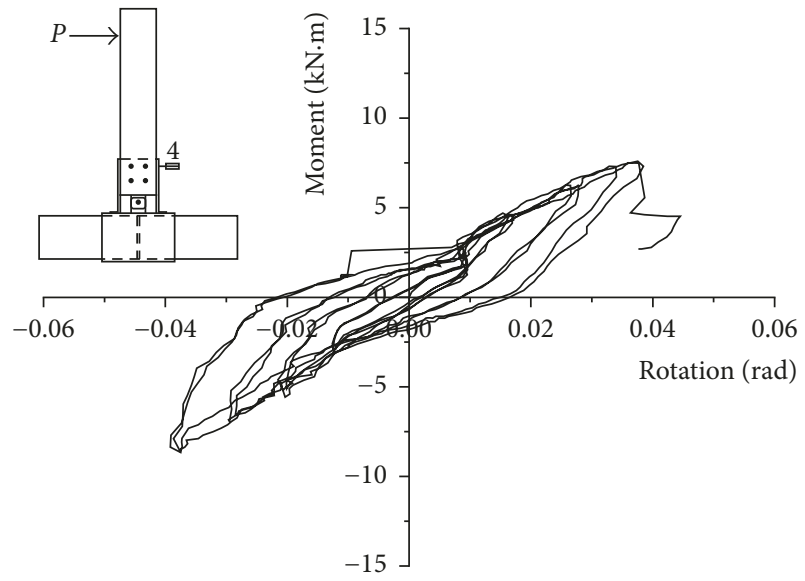

FIGURE 11: Moment-rotation hysteretic curve of the specimen CJ1.

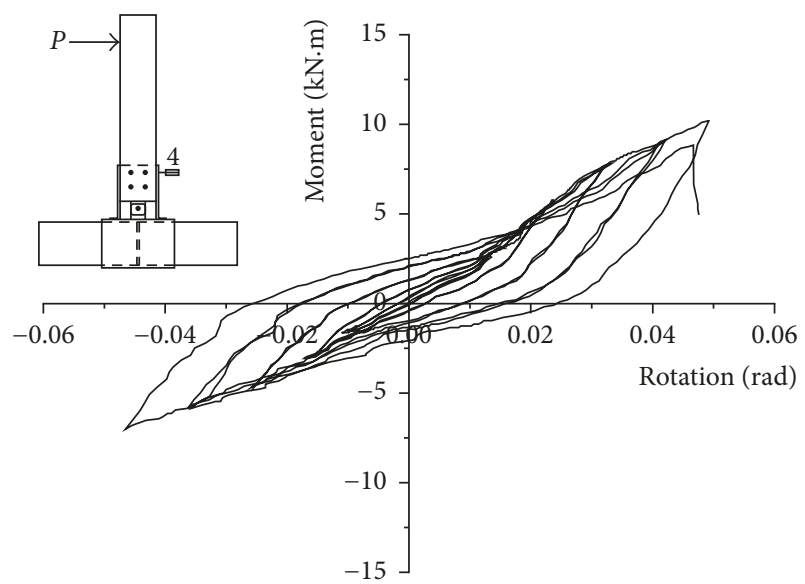

FIGURE 12: Moment-rotation hysteretic curve of the specimen CJ2.

each specimen. This indicates that the thickness of the hollow steel column has an influence on the strength of connection.

It is also observed that the envelope curve under compressive load is different from the envelope curve under tensile load. This is due to the stiffness degradation of the steel plate.

4.5. Energy Dissipation. The energy dissipation of the connection is the enclosed area under cyclic loading, as shown in Figure 15, and the displacement in Figure 15 is the maximum beam tip displacement. It is an important index for evaluating seismic performance of the joint.

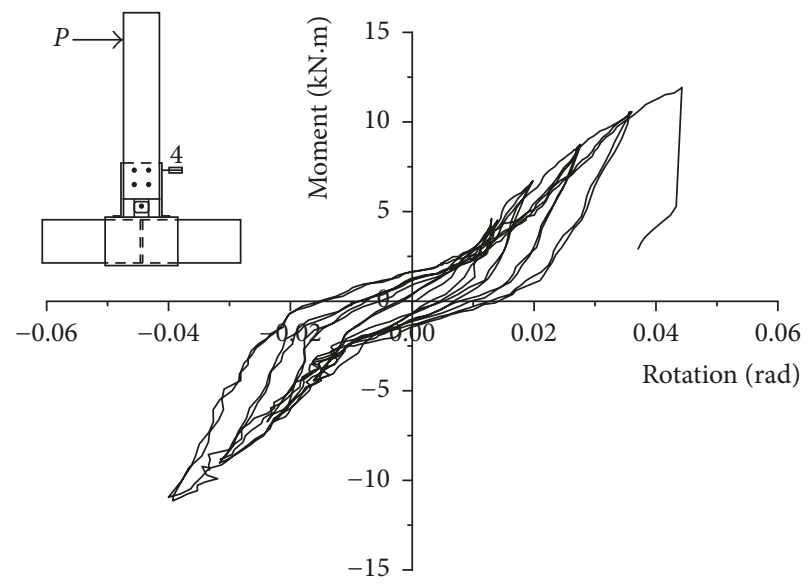

FIGURE 13: Moment-rotation hysteretic curve of the specimen CJ3.

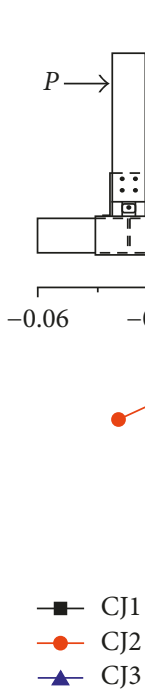

FIgURE 14: Envelope curve of the specimen under cyclic loading.

According to literature [25], the energy dissipation capacity coefficient $E$ can be expressed in the following equation:

$$
E=\frac{S_{\mathrm{ABD}}+S_{\mathrm{CBD}}}{S_{\mathrm{OAE}}+S_{\mathrm{OCF}}}
$$

Coefficient $E$ for the three specimens CJ1, CJ2, and CJ3 is $1.70,1.77$, and 1.67 , respectively. It can be seen that the specimen CJ2 has the biggest coefficient $E$, and the specimen 


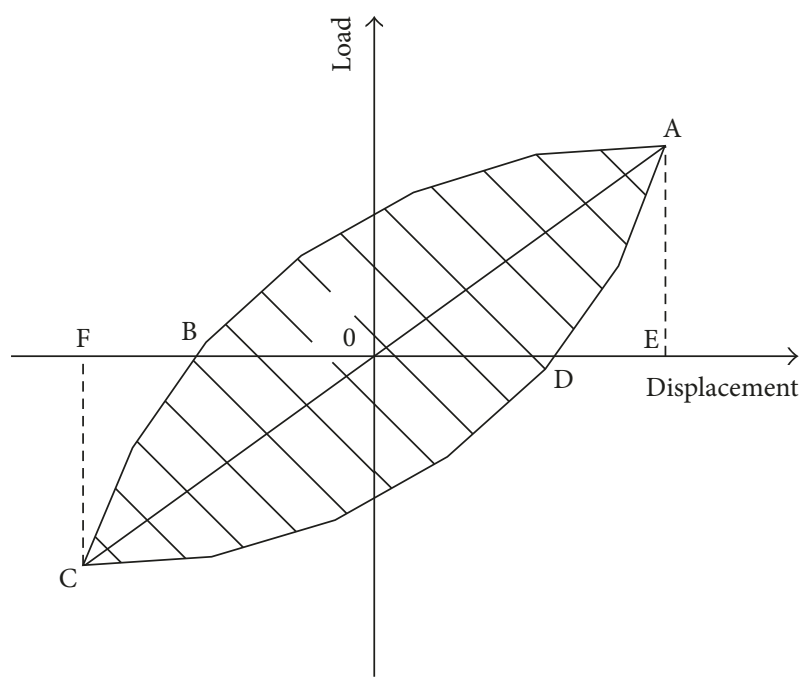

FiguRE 15: Enclosed area under cyclic loading.

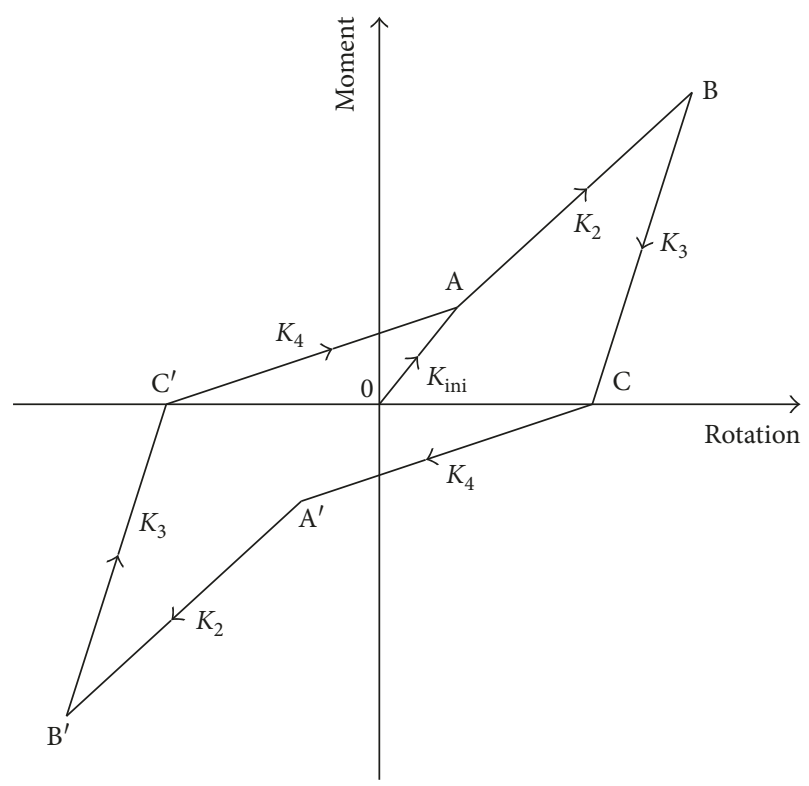

FIgURE 16: Hysteresis model of connection.

CJ3, which has the thickest hollow steel column, has the lowest coefficient $E$.

4.6. Hysteresis Model of Connections. Based on the momentrotation curves showed in Figures 11-13, the simplified hysteresis model of the joint under cyclic loading is showed in Figure 16. Point $A$ is the summit point of the first step cycle, and from point 0 to point $A$, the loading stiffness is expressed with secant stiffness $K_{\text {ini }}$. After passing point A, loading stiffness $K_{2}$ becomes smaller. This is due to the shear deformation of the beam and bending deformation of the hollow steel column. $K_{3}$ is the unloaded stiffness from point $\mathrm{B}$, which is obviously larger than the loading stiffness $K_{2}$. At the start of unloading, only beam flanges act in tension and compression, and shear deformation of the beam and
TABLE 5: Model parameters of the specimens.

\begin{tabular}{lcccc}
\hline \multirow{2}{*}{ Specimen } & \multicolumn{4}{c}{ Stiffness $(\mathrm{kN} \cdot \mathrm{m} / \mathrm{rad})$} \\
& $K_{\text {ini }}$ & $K_{2}$ & $K_{3}$ & $K_{4}$ \\
\hline CJ1 & 333 & 166 & 498 & 170 \\
CJ2 & 221 & 205 & 309 & 116 \\
CJ3 & 354 & 263 & 501 & 137 \\
\hline
\end{tabular}

bending deformation of the column plate were not happening. When the unloading reaches zero, the loading in the opposite direction starts.

When the load starts to load in the opposite direction, the shear deformation of the beam and deflection of the hollow steel column recover first along with the close of the gap between the shear connection plate and the bolt, followed by the load increase of the joint. Therefore, the hysteretic curve of connection has slight pinching, and the stiffness of the slope is called as slippage stiffness $K_{4}$. Based on the tested results, the average stiffness values $K_{\text {ini }}, K_{2}, K_{3}$, and $K_{4}$ of each specimen are given in Table 5, in which $K_{2}$, $K_{3}$, and $K_{4}$ are the slopes of regression lines.

\section{Conclusions}

In this study, the mechanical performance of a new type connector in timber frame building was investigated. Three full-scale specimens with different hollow steel column thicknesses were subjected to cyclic loading up to failure, and the primary conclusions can be summarized as follows.

For the three specimens, failures were due to the compression buckling of the beam flange, and yielding in the beam flange was not observed. In addition, deformation perpendicular to the hollow steel column was observed in the specimen CJ2; however, no obvious deformation was noted in the specimens CJ1 and CJ3. Buckling of the beam flange governs the moment resistance and rotation capacity of connection.

It is also noticed that the hysteresis loops for the three specimens appear full, with slight pinching in every specimen. The energy dissipation coefficient $\mathrm{E}$ for the three specimens CJ1, CJ2, and CJ3 is 1.70, 1.77, and 1.67, respectively, which indicates that the three specimens have good energy dissipation. The hollow steel column thickness has significant influence on the energy dissipation of the connection. Although the thinner hollow steel column has better energy dissipation, it has less connection stiffness.

The maximum rotations of the specimens CJ1, CJ2, and CJ3 under cyclic loading are $0.0375,0.049$, and 0.044 , respectively. The thinner the hollow steel column, the larger the rotation of the connection.

Under the cyclic loading, the connection undergoes substantial losses in stiffness.

According to the envelope curve and moment-rotation curve, a hysteresis model for this type of connection under cyclic loading is presented. Employing a thick hollow steel column will have bigger first secant stiffness $K_{\text {ini }}$ under cyclic loading. 


\section{Conflicts of Interest}

The authors declare that they have no conflicts of interest.

\section{Acknowledgments}

This research was supported by the National Natural Science Foundation of China (nos. 51778299 and 51578291), the Priority Academic Program Development of Jiangsu Higher Education Institutions, the Project of Housing and UrbanRural Development Ministry of China (no. 2014-K2-014), and the Science Foundation of Changzhou Institute of Technology (no. YN1615).

\section{References}

[1] D. P. Fang, S. Iwasaki, M. H. Yu, Q. P. Shen, Y. Miyamoto, and H. Hikosaka, "Ancient Chinese timber architecture. I: experimental study," Journal of Structural Engineering, vol. 127, no. 11, pp. 1348-1357, 2001.

[2] W. S. King, J. Y. Richard Yen, and Y. N. Alex Yen, "Joint characteristics of traditional Chinese wooden frames," Engineering Structures, vol. 18, no. 8, pp. 635-644, 1996.

[3] Q. Chun, Z. Yue, and J. W. Pan, "Experimental study on seismic characteristics of typical mortise-tenon joints of Chinese southern traditional timber frame buildings," Science China Technological Sciences, vol. 54, no. 9, pp. 2404-2411, 2011.

[4] W. S. Chang, J. Shanks, A. Kitamori, and Kohei Komatsu, "The structural behavior of timber joints subjected to bi-axial bending," Earthquake Engineering \& Structural Dynamics, vol. 38, no. 6, pp. 739-757, 2009.

[5] J. M. Seo, I. K. Choi, and J. R. Lee, "Static and cyclic behavior of wooden frames with tenon joints under lateral load," Journal of Structural Engineering, vol. 125, no. 3, pp. 344-349, 1999.

[6] W. M. Bulleit, L. Bogue Sandberg, M. W. Drewek, and T. L. O'Bryant, "Behavior and modeling of wood-pegged timber frames," Journal of Structural Engineering, vol. 125, no. 1, pp. 3-9, 1999.

[7] J. P. Hong, J. David Barrett, and F. Lam, "Three-dimensional finite element analysis of the Japanese traditional post-andbeam connection," Journal of Wood Science, vol. 57, no. 2, pp. 119-125, 2011.

[8] F. Lam, M. Schulte-Wrede, C. C. Yao et al., "Moment resistance of bolted timber connections with perpendicular to grain reinforcements," in Proceedings of the 10th World Conference on Timber Engineering (WCTE), Miyazaki, Japan, June 2008.

[9] F. Lam, M. Gehloff, and M. Closen, "Moment-resisting bolted timber connections," Proceedings of the Institution of Civil Engineers-Structures and Buildings, vol. 163, no. 4, pp. 267274, 2010.

[10] M. Q. Wang, X. B. Song, X. L. Gu, Y. Zhang, and L. Luo, "Rotational behavior of bolted beam-to-column connections with locally cross-laminated glulam," Journal of Structural Engineering, vol. 141, no. 4, pp. 1-7, 2015.

[11] M. Fragiacomo and M. Batchelar, "Timber frame moment joints with glued-in steel rods. I: design," Journal of Structural Engineering, vol. 138, no. 6, pp. 789-801, 2012.

[12] M. Fragiacomo and M. Batchelar, "Timber frame moment joints with glued-in steel rods. II: experimental investigation of long-term performance," Journal of Structural Engineering, vol. 138, no. 6, pp. 802-811, 2012.

[13] G. Tlustochowicz, E. Serrano, and R. Steiger, "State-of-the-art review on timber connections with glued-in steel rods," Materials and Structures, vol. 44, no. 5, pp. 997-1020, 2011.

[14] M. Vašek and R. Vyhnálek, "Timber semi rigid frame with glued-in-rods joints," in Proceedings of the 9th World Conference on Timber Engineering (WCTE), August 2006.

[15] M. Vašek, "Semi rigid timber frame and space structure connections by glued-in rods," in Proceedings of the 10th World Conference on Timber Engineering (WCTE), Miyazaki, Japan, June 2008.

[16] A. Bouchaïr, P. Racher, and J. F. Bocquet, "Analysis of dowelled timber to timber moment-resisting joints," Materials and Structures, vol. 40, no. 10, pp. 1127-1141, 2007.

[17] T. Tsuchimoto, N. Ando, T. Arima et al., "Effect of clearance on the mechanical properties of timber joint," in Proceeding of Pacific timber engineering conference, vol. 2, pp. 204210pp. 204-210, Rotorua, New Zealand, March 1999.

[18] D. S. Huang, A. P. Zhou, Q. S. Zhang et al., "Quasi-static experimental research on energy dissipating joints for assembled timber frame structures," Journal of Building Structures, vol. 32, no. 7, pp. 87-92, 2011, in Chinese.

[19] D. S. Huang, A. P. Zhou, and Y. L. Bian, "Experimental and analytical study on the nonlinear bending of parallel strand bamboo beams," Construction and Building Materials, vol. 44, pp. 191-196, 2013.

[20] D. S. Huang, Y. L. Bian, A. P. Zhou, and B. Sheng, "Experimental study on stress-strain relationships and failure mechanisms of parallel strand bamboo made from phyllostachys," Construction and Building Materials, vol. 77, pp. 130-138, 2015.

[21] D. S. Huang, Y. L. Bian, D. M. Huang, A. Zhou, and B. Sheng, "An ultimate-state-based-model for inelastic analysis of intermediate slenderness PSB columns under eccentrically compressive load," Construction and Building Materials, vol. 94, pp. 306-314, 2015.

[22] GB/T 700-2006, "Carbon structural steels" (in Chinese)," 2007.

[23] European Standard EN 10002-1, Metallic Materials-Tensile Testing-Part 1: Method of Testing at Ambient Temperature, CEN, Brussels, Belgium, 2001.

[24] The American Society for Testing and Materials, ASTM D143-09, Standard Test Methods for Small Clear Specimens of Timber, ASTM, West Conshohocken, PA, USA, 2009.

[25] JGJ/T 101-2015, Specification for Seismic Test of Building, China Construction Industry Press, Beijing, 2015, in Chinese. 


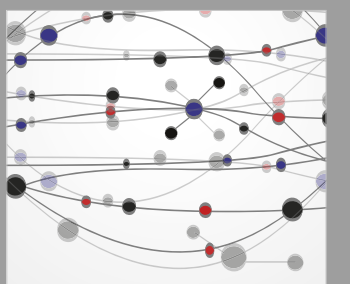

The Scientific World Journal
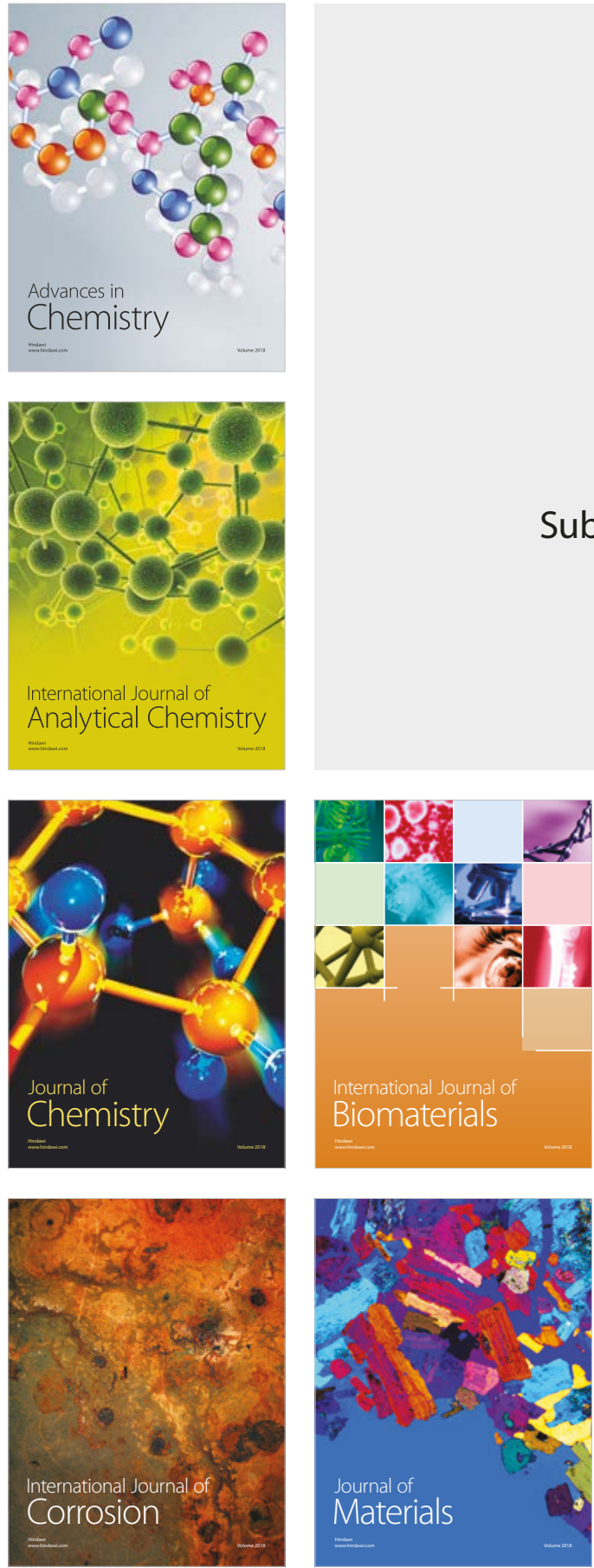

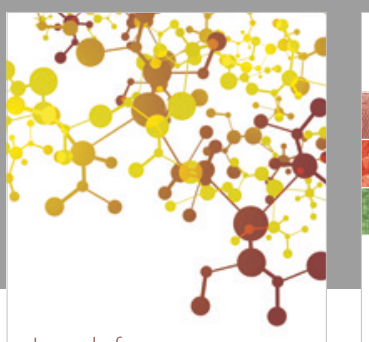

Journal of

Applied Chemistry
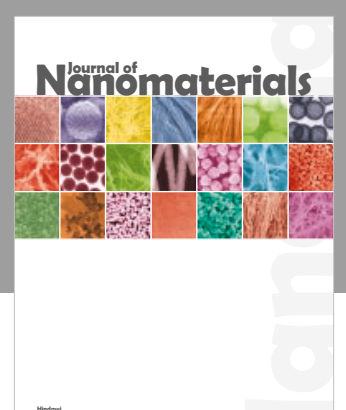

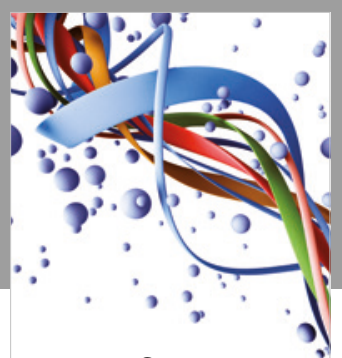

Scientifica

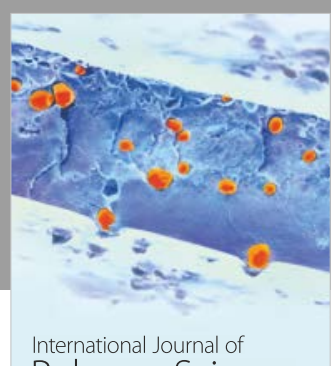

Polymer Science

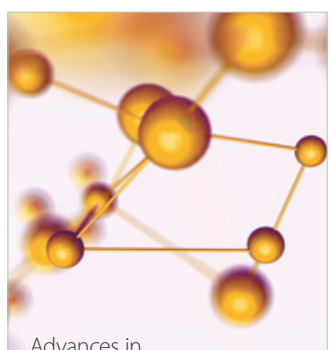

Physical Chemistry
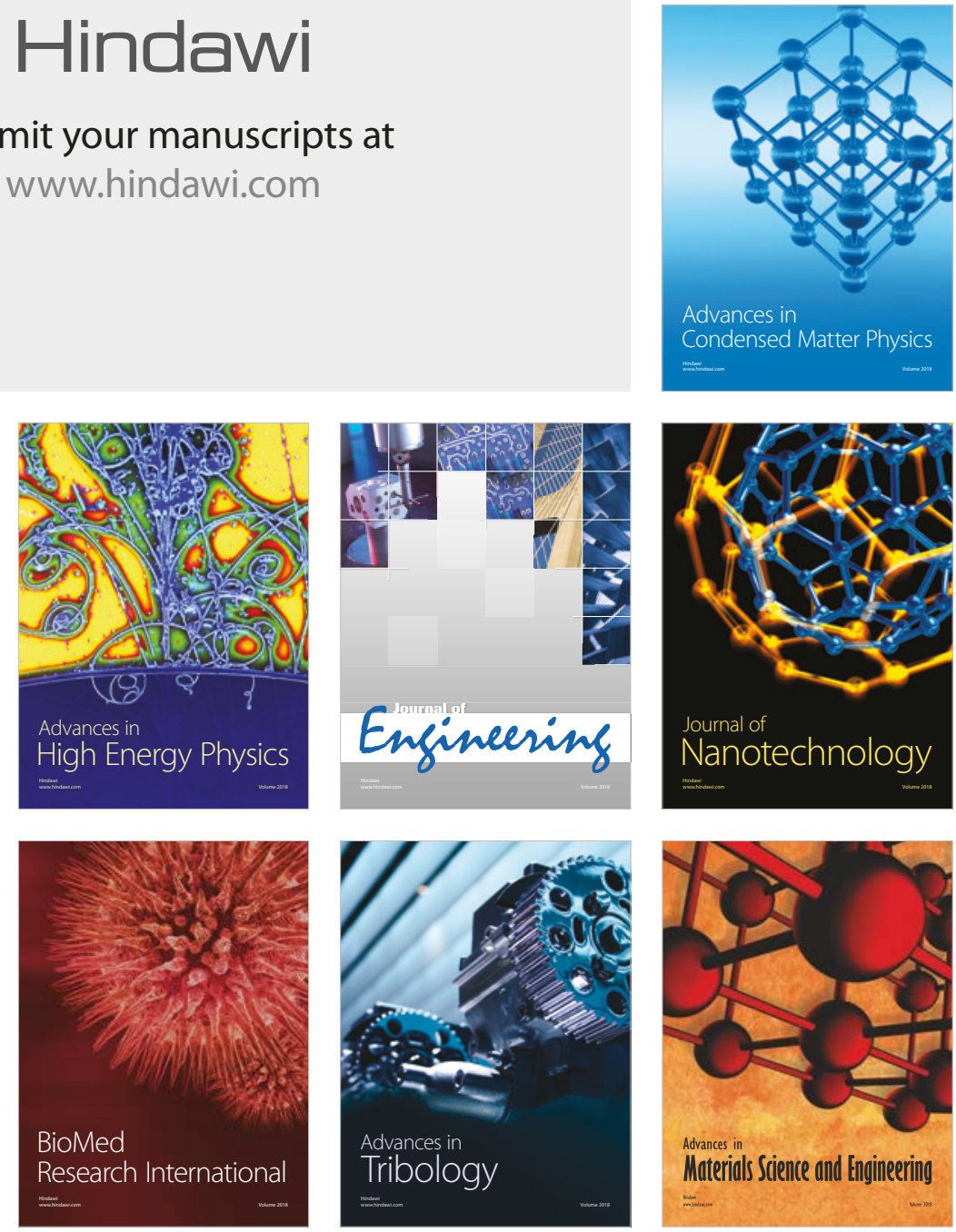